Georgia State University

ScholarWorks @ Georgia State University

\title{
Intergovernmental Fiscal Relations: the Efficiency Effect of Taxes, Transfers and Fiscal Illusion
}

Julio Lopez-Laborda

University of Zaragoza, julio.lopez@unizar.es

Antoni Zabalza

University of Valencia, antonio.zabalza@un.es

Follow this and additional works at: https://scholarworks.gsu.edu/icepp

Part of the Economics Commons

\section{Recommended Citation}

Lopez-Laborda, Julio and Zabalza, Antoni, "Intergovernmental Fiscal Relations: the Efficiency Effect of Taxes, Transfers and Fiscal Illusion" (2012). ICEPP Working Papers. 73.

https://scholarworks.gsu.edu/icepp/73

This Working Paper is brought to you for free and open access by the International Center for Public Policy at ScholarWorks @ Georgia State University. It has been accepted for inclusion in ICEPP Working Papers by an authorized administrator of ScholarWorks @ Georgia State University. For more information, please contact scholarworks@gsu.edu. 
INTERNATIONAL CENTER FOR PUBLIC POLICY
International Center for Public Policy Working Paper 12-29

September 2012
Intergovernmental Fiscal Relations: the Efficiency Effect of Taxes, Transfers and Fiscal Illusion

Julio López-Laborda Antoni Zabalza 

International Center for Public Policy

Working Paper 12-29

\section{Intergovernmental Fiscal Relations: the Efficiency Effect of Taxes, Transfers and Fiscal Illusion}

Julio López-Laborda

Antoni Zabalza

September 2012

International Center for Public Policy

Andrew Young School of Policy Studies

Georgia State University

Atlanta, Georgia 30303

United States of America

Phone: (404) 651-1144

Fax: (404) 651-4449

Email: hseraphin@gsu.edu

Internet: http://aysps.gsu.edu/isp/index.html

Copyright 2006, the Andrew Young School of Policy Studies, Georgia State University. No part of the material protected by this copyright notice may be reproduced or utilized in any form or by any means without prior written permission from the copyright owner. 


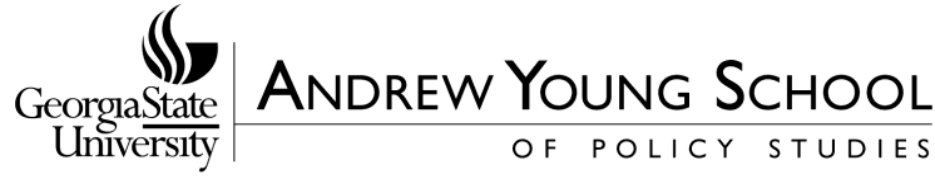

\section{International Center for Public Policy Andrew Young School of Policy Studies}

The Andrew Young School of Policy Studies was established at Georgia State University with the objective of promoting excellence in the design, implementation, and evaluation of public policy. In addition to two academic departments (economics and public administration), the Andrew Young School houses seven leading research centers and policy programs, including the International Center for Public Policy.

The mission of the International Center for Public Policy is to provide academic and professional training, applied research, and technical assistance in support of sound public policy and sustainable economic growth in developing and transitional economies.

The International Center for Public Policy at the Andrew Young School of Policy Studies is recognized worldwide for its efforts in support of economic and public policy reforms through technical assistance and training around the world. This reputation has been built serving a diverse client base, including the World Bank, the U.S. Agency for International Development (USAID), the United Nations Development Programme (UNDP), finance ministries, government organizations, legislative bodies and private sector institutions.

The success of the International Center for Public Policy reflects the breadth and depth of the in-house technical expertise that the International Center for Public Policy can draw upon. The Andrew Young School's faculty are leading experts in economics and public policy and have authored books, published in major academic and technical journals, and have extensive experience in designing and implementing technical assistance and training programs. Andrew Young School faculty have been active in policy reform in over 40 countries around the world. Our technical assistance strategy is not to merely provide technical prescriptions for policy reform, but to engage in a collaborative effort with the host government and donor agency to identify and analyze the issues at hand, arrive at policy solutions and implement reforms.

The International Center for Public Policy specializes in four broad policy areas:

- Fiscal policy, including tax reforms, public expenditure reviews, tax administration reform

- Fiscal decentralization, including fiscal decentralization reforms, design of intergovernmental transfer systems, urban government finance

- Budgeting and fiscal management, including local government budgeting, performancebased budgeting, capital budgeting, multi-year budgeting

- Economic analysis and revenue forecasting, including micro-simulation, time series forecasting,

For more information about our technical assistance activities and training programs, please visit our website at http://aysps.gsu.edu/isp/index.html or contact us by email at hseraphin@gsu.edu. 


\title{
Intergovernmental Fiscal Relations: the Efficiency Effect of Taxes, Transfers and Fiscal Illusion ${ }^{1}$
}

\author{
Julio López-Laborda* and Antoni Zabalza** \\ *Department of Public Economics, University of Zaragoza \\ ** Department of Economic Analysis, University of Valencia
}

\begin{abstract}
The purpose of this paper is to evaluate the efficiency cost of transfers. To this end, we develop a model of individual demand decisions about the provision of a regional public good that encompasses a continuum of tax/transfers scenarios to finance regional public expenditure. We assume that individuals have identical quasilinear preferences defined over private consumption and the regional public good, that endowment income varies between individuals and regions and that regions have different predetermined sizes. We show that, despite its simplicity, this model is capable of discriminating the efficiency properties of the different scenarios considered, and that the substitution of transfers for own regional taxes always raises the provision of the regional public good. Our model yields the so called "flypaper effect" with no need to appeal to the existence of "fiscal illusion" by the part of the individual. We nevertheless find that "fiscal illusion" increases the elasticity of public good provision with respect to transfers, and we suggest two potentially refutable hypotheses to identify the existence of this phenomenon.
\end{abstract}

KEYWORDS: Regional finance, taxes, transfers, fiscal illusion, flypaper effect.

JEL CLASSIFICATION: H7

\footnotetext{
${ }^{1}$ We are indebted to Robin Boadway, Diego Martínez-López and François Vaillancourt for their helpful comments and suggestions to a previous draft of this article. Julio López-Laborda would like to thank the Spanish Ministry of Science and Innovation (project ECO2009-10003), the Government of Aragon and the European Social Fund (Public Economics research group) for financial help.
} 


\section{Introduction}

Arguably, one of the most important problems regarding the design of federal systems is the allocation of revenue sources among different levels of government, so that expenditure responsibilities can be adequately financed. Theoretical alternatives range from the attribution to each jurisdiction of its own taxes, to the attribution of all taxes to the central jurisdiction together with the implementation of transfers to finance subcentral levels of government (henceforth "regions"). In practice, no federal country applies any of these two pure models. Normally, own regional taxes play a predominant, but not exclusive role. They tend to be complemented by central government transfers aimed at diverse objectives, such as the compensation of horizontal and vertical fiscal gaps, the correction of externalities, the promotion of regional development and the imposition of national minimum standards in the provision of particular regional services. ${ }^{2}$

The literature on fiscal federalism has dealt extensively with this subject. The identification of taxes that are susceptible of being decentralized is a recurrent topic since the seminal contribution by Musgrave (1983). ${ }^{3}$ Also, the work by Gordon (1983) opened an extensive literature on the consequences of the use of distortionary taxes by regional governments, among which we find the emergence of fiscal externalities, both horizontal (tax exporting and fiscal competition between regions) and vertical (due to the sharing of tax bases by the central and regional levels of government). ${ }^{4}$ The other main area of growing interest is the typology, purpose and economic effects of intergovernmental transfers, with particular attention to equalizing grants and to the flypaper effect. ${ }^{5}$

The purpose of this paper is to evaluate the efficiency cost of transfers. This is a modest endeavour compared with the contributions cited above, but nevertheless a necessary task that, in a sense, deals with a question previous to the issues considered above. There is a wide agreement in the literature on the prevalence of taxes over

\footnotetext{
${ }^{2}$ See Shah, ed. (2007) and Boadway (2012).

${ }^{3}$ For a recent discussion of the tax assignment problem see Boadway and Shah (2009).

${ }^{4}$ Recent treatments of these topics can be found in Wilson (2006), Dahlby (2008, ch. 9) and Boadway and Shah (2009).

5 Buchanan (1950) and Musgrave (1961) are the two seminal contributions on equalising transfers. Boadway and Shah (2009) offer a complete analysis of the theory and practice of interjurisdictional transfers. We return to the flypaper effect below in this work.
} 
transfers among the instruments of regional finance. The standard political argument is that own taxes make it possible the fiscal autonomy of regions and, from an economic point of view, it is argued that taxes force regional governments to be fiscally accountable before its electors, a circumstance that favours the efficient provision of public goods and services. ${ }^{6}$ Transfer finance, on the other hand, weakens fiscal autonomy and accountability and leads to wrong decisions concerning public expenditure. Our objective in this paper is to formalize this argument in a systematic manner and to identify the efficiency gains associated with own regional taxes with regard to other formulas, such as all transfer or mixed tax/transfer methods of regional finance. As far as we know, this has not been done before.

To this end, we develop a model based on individual demand decisions concerning the level of the regional public good, where individuals have identical quasi-linear preferences defined over private consumption and a regional public good, and where only endowment income varies between individuals and regions. Regions, on the other hand, have different predetermined sizes. This is admittedly a very simple model, but we show that it is sufficient to make the efficiency properties of the several scenarios considered visible. This is done in the context of non distortionary taxation, but we argue as well that the results obtained are very likely to hold in an economy in which taxes impose an efficiency cost. If the "flypaper effect" is defined as the increase in public good provision as the result of substituting transfers for own regional taxes, then our model yields this effect with no need to appeal to the existence of "fiscal illusion" by the part of the individual. We nevertheless find that "fiscal illusion" increases the elasticity of public good provision with respect to transfers, and we suggest two potentially refutable hypotheses to empirically identify the existence of this phenomenon.

The article is organized as follows. In Section 2 we identify the reference point that will be used all along the paper: the Pareto efficient provision of the regional public good. In Section 3 we develop a model that generates a continuum of tax/transfer mix scenarios and use this framework to analyse their efficiency under the collective decision rule of simple majority. In this model, the transfer is a given fraction of the cost of the public good. This section is complemented with an Annex in which we extend the results of Section 3 to an economy with distortionary taxation. In Section 4

\footnotetext{
${ }^{6}$ Here, again, the literature is huge. See, for all, Bird (1993).
} 
we consider a variant of the tax/transfer mix, in which the transfer is independent of the level of provision of the public good. We show that when an exogenous transfer is used along with marginal taxation by regions, and under certain restrictions, these two sources of revenue are interchangeable and Pareto efficiency is achieved. In Section 5 we review other scenarios of interest - tax revenue sharing and tax sharing complemented with own regional taxes- and show that they can be assimilated to some of the basic scenarios considered in Sections 3 and 4. In Section 6 we define the concept of "fiscal illusion" and apply it to the different scenarios identified in the paper. We show that fiscal illusion does not have an effect in all circumstances, but that there are certain scenarios in which a flypaper-type effect arises; in this respect we identify two hypotheses which are empirically testable. Section 7 ends the paper with some concluding remarks and a summary of the main results obtained.

\section{Pareto efficient equilibrium}

Let us consider, as in Persson and Tabellini (2000), a country formed by $J$ regions, each with $N_{j}$ individuals. The country's population is $N$, where $N=\sum_{j} N_{j}$. Individual $i$ of region $j$ has the following quasi-linear utility function

$$
w_{i j}=c_{i j}+H\left(g_{j}\right) \text {, }
$$

where $c_{i j}$ is his consumption of private goods and $H(\cdot)$ an increasing concave function defined over a regionally provided public good with no inter-region spillovers $g_{j}{ }^{7}$ All individuals have the same preferences. In all regions, a unit of income can be transformed without cost into a unit of the public good. If we denote the cost of the public good by $c\left(g_{j}\right)$, then $c\left(g_{j}\right) \equiv g_{j}$, so the marginal cost of providing the public good is $d c\left(g_{j}\right) / d g_{j}=1$. There is no mobility between jurisdictions and the central

\footnotetext{
${ }^{7}$ The same results we obtain in this paper would follow if instead we considered a publicly provided private good.
} 
government provides a national public good $g_{c}$ that is financed with a lump sum central tax paid by the total country's population. ${ }^{8}$

To obtain the efficient level of provision of $g_{j}$, the regional government maximizes the sum of utilities of region $j$ 's inhabitants with respect to $g_{j}$

$$
\underset{g_{j}}{\operatorname{Max}} W_{j}=\sum_{i} w_{i j}=\sum_{i} c_{i j}+N_{j} H\left(g_{j}\right)
$$

subject to the resource constraint:

$$
g_{j}+\sum_{i} c_{i j}=\sum_{i} y_{i j}
$$

where $y_{i j}$ is the individual's endowment income, $m_{i j}$, net of the lump sum central tax. That is, $y_{i j}=m_{i j}-\left(g_{c} / N\right)$. Since our interest is on the level of provision of the regional public good, in what follows we take the tax $g_{c} / N$ as given and work directly with $y_{i j}$.

Substituting the resource constraint into $W_{j}$, the expression to be maximized is

$$
W_{j}=\sum_{i} y_{i j}-g_{j}+N_{j} H\left(g_{j}\right)
$$

and the first order condition is

$$
\frac{d W_{j}}{d g_{j}}=-1+N_{j} H_{g}\left(g_{j}^{*}\right)=0
$$

or

$$
N_{j} H_{g}\left(g_{j}^{*}\right)=1, \quad \forall j
$$

At the efficient level of provision, $g_{j}^{*}$, the sum over all $J$ inhabitants of the marginal rates of substitution between the public good and private consumption will equal the marginal cost. This is the Samuelson (1954) condition and constitutes the reference position that we shall use in this exercise to evaluate the different tax/transfer structures under consideration.

\footnotetext{
${ }^{8}$ The existence of a national public good is not crucial to our argument, and could perfectly well be ignored, assuming that the only central government responsibility is to raise national taxes in order to fund transfers to the regions.
} 
Notice that with quasi-linear preferences the efficient amount of the public good is independent of the level of private consumption. This is readily seen in (2), which determines a unique level of $g_{j}$ with independence from the optimal level of $c_{i j}$. Another implication of this assumption is that income effects are zero as far as the efficient amount of the public good is concerned.

Can this social optimum be obtained as the result of individual behaviour and majority rule? In what follows, we explore this question using the simple model developed above and in the context of several alternative ways of financing the regional public good.

\section{A model of the tax/transfer mix}

\subsection{Lump sum tax finance}

Suppose that in general regional governments finance their public expenditure by means of own taxes and transfers from the central government. In this section we consider that only lump-sum taxation is available to both levels of government in order to collect their own taxes or to fund transfers. Transfers from the central government are a compensatory mechanism to help regional governments to pay for their expenditure; that is

$$
s_{j}=\gamma g_{j}, \forall j
$$

where $\gamma$ is the fraction of the cost of the regional public good that is covered by the transfer, $0 \leq \gamma \leq 1{ }^{9}$

With lump-sum finance, the budget constraint faced by individual $i$ of region $j$ is

$$
c_{i j}=y_{i j}-\frac{s}{N}-\frac{g_{j}-s_{j}}{N_{j}}
$$

Where $s$ is the total transfer and $s / N$ the lump-sum tax that the central government collects from all national residents in order to fund this transfer. Given this transfer, the regional government finances the uncovered cost of the public good by means of a

\footnotetext{
${ }^{9}$ At this level of generality, transfers can be thought of as open-ended and, given $\gamma$, dependent on the optimal level of $g_{j}$. Mathematically, the parameter $\gamma$ is a shift parameter that measures the relative importance of transfers in the regional finance system.
} 
lump-sum tax $\left(g_{j}-s_{j}\right) / N_{j}$ levied on the residents of the region. Using (3), this budget constraint can be rewritten as

$$
c_{i j}=y_{i j}-\gamma \frac{g}{N}-(1-\gamma) \frac{g_{j}}{N_{j}},
$$

where $g=\sum_{j} g_{j}$, or

$$
c_{i j}=y_{i j}-\frac{\gamma}{N} \sum_{k \neq j} g_{k}-\left[\gamma \frac{1}{N}+(1-\gamma) \frac{1}{N_{j}}\right] g_{j} .
$$

Expression (4) tells us that, in general, the budget constraint faced by the individual has, in the $\left(c_{i j}, g_{j}\right)$ space, a vertical intercept equal to

$$
y_{i j}-\frac{\gamma}{N} \sum_{k \neq j} g_{k}
$$

and a constant slope, the absolute value of which is

$$
\gamma \frac{1}{N}+(1-\gamma) \frac{1}{N_{j}}
$$

This framework allows us to identify the following three finance scenarios.

\section{Own regional tax scenario}

If $\gamma=0$-that is, there is no transfer and the region finances its public good by means of a lump-sum tax levied on its residents - then (4) gets reduced to

$$
c_{i j}=y_{i j}-\frac{g_{j}}{N_{j}}
$$

which is the steepest budget line of Figure 1, with vertical intercept $y_{i j}$ and slope (absolute value) $1 / N_{j} \cdot 10$

Substituting (5) into the individual's utility function (1), we have

\footnotetext{
${ }^{10}$ Unless indicated otherwise, in what follows slopes are always measured by means of their absolute value.
} 


$$
w_{i j}=y_{i j}-\frac{g_{j}}{N_{j}}+H\left(g_{j}\right)
$$

His demand for the public good will satisfy the first order condition

$$
\frac{d w_{i j}}{d g_{j}}=-\frac{1}{N_{j}}+H_{g}\left(g_{j}^{t}\right)=0,
$$

or

$$
N_{j} H_{g}\left(g_{j}^{t}\right)=1, \forall j
$$

where $g_{j}^{t}$ is the level of provision of the regional public good demanded by individuals when this good is financed with a regional lump sum tax.

\section{Figure 1: Tax/transfer mix equilibriums}

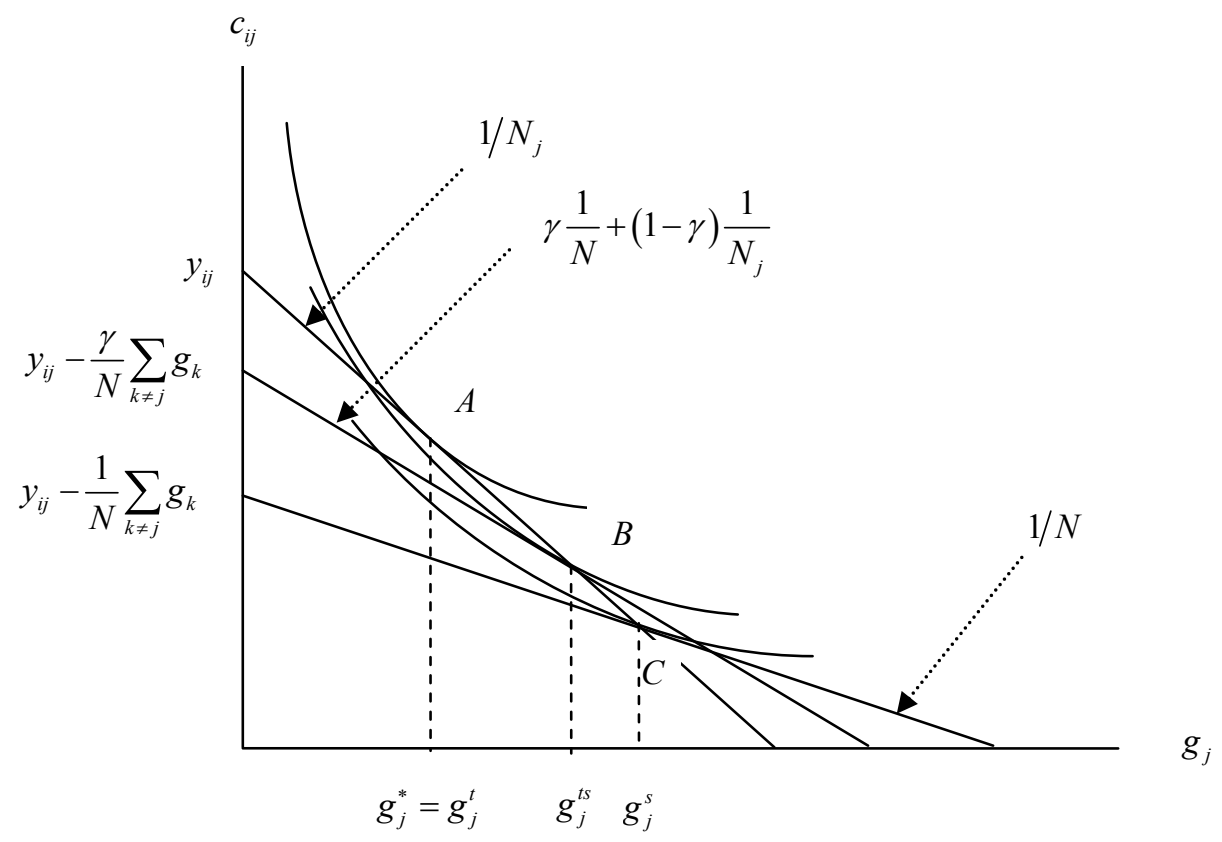


Comparing (2) and (6) we conclude that $g_{j}^{t}=g_{j}^{*}$. The social optimum emerges as an equilibrium if the public good is financed with a regional lump sum tax. ${ }^{11}$ See also that this is the demand of all individuals in region $J$. Under the assumption of identical quasi linear preferences there is unanimity concerning the demand of the public good, which in Figure 1 is represented by point $A$.

\section{Transfer scenario}

If $\gamma=1$-that is, the regional government obtains all the finance needed through a transfer from the central government- then (4) gets reduced to

$$
c_{i j}=y_{i j}-\frac{1}{N} \sum_{k \neq j} g_{k}-\frac{g_{j}}{N}
$$

which is the flattest budget line in Figure 1, with vertical intercept $y_{i j}-\left(\sum_{k \neq j} g_{k} / N\right)$ and slope $1 / N$. In this case, the individual's indirect utility is

$$
w_{i j}=y_{i j}-\frac{1}{N} \sum_{k \neq j} g_{k}-\frac{g_{j}}{N}+H\left(g_{j}\right)
$$

and the level of provision of the public good, $g_{j}^{s}$, must satisfy the first order condition

$$
\frac{d w_{i j}}{d g_{j}}=-\frac{1}{N}+H_{g}\left(g_{j}^{s}\right)=0,
$$

or

$$
H_{g}\left(g_{j}^{s}\right)=\frac{1}{N}
$$

Multiplying both sides of this expression by $N_{j}$ we have

$$
N_{j} H_{g}\left(g_{j}^{s}\right)=\frac{N_{j}}{N}, \forall j
$$

\footnotetext{
${ }^{11}$ See Bowen (1943), Casahuga (1982), and Brennan and Buchanan (1983).
} 
and comparing (2) and (7) it follows that $g_{j}^{s}>g_{j}^{*}, \forall j$, since $N_{j} / N<1$. All regions over provide the regional public good in comparison with the Pareto efficient level. This is point $C$ in Figure 1.

We have here the familiar common-pool problem: ${ }^{12}$ each region internalizes the whole of the benefits generated by its own public good, but, as finance is shared with other regions, it only internalizes a fraction $N_{j} / N$ of the marginal cost. Transfer finance, therefore, generates financial irresponsibility by the part of the region, while keeping its autonomy in deciding the level at which the public good must be provided.

\section{Tax/transfer mix scenario}

Finally, if $0<\gamma<1$-that is, if regional finance is obtained by a mix between own tax and transfer from the central government- then the relevant budget constraint is the same expression (4). The tax-price of the public good faced by the individual is a weighted average of the tax-price associated to the all transfer scenario, $1 / N$, and that associated to the own tax scenario, $1 / N_{j}$, where the weighting factor is the transfer coverage parameter $\gamma$. This is the middle budget line of Figure 1, with vertical intercept $y_{i j}-\gamma\left(\sum_{k \neq j} g_{k} / N\right)$ and slope $\gamma(1 / N)+(1-\gamma)\left(1 / N_{j}\right)$.

Substituting (4) into the individual's utility function we have

$$
w_{i j}=y_{i j}-\frac{\gamma}{N} \sum_{k \neq j} g_{k}-\left[\gamma \frac{1}{N}+(1-\gamma) \frac{1}{N_{j}}\right] g_{j}+H\left(g_{j}\right),
$$

with first order condition

$$
H_{g}\left(g_{j}^{t s}\right)=\gamma \frac{1}{N}+(1-\gamma) \frac{1}{N_{j}}
$$

or

$$
N_{j} H_{g}\left(g_{j}^{t s}\right)=1-\gamma\left(1-\frac{N_{j}}{N}\right), \forall j
$$

This is equilibrium $B$ in Figure 1. If transfers have an element of compensation linked to the provision of the regional public good, their introduction into the system,

\footnotetext{
12 The so called “1/N law”. See Weingast, Shepsle and Johnsen (1981).
} 
even if they are complemented with taxes, will generate a distortion in the tax-price, and generate an over provision, of the public good. The distortion, and therefore the over provision, will be larger the more important is the transfer in relation to the cost of the public good; that is, the larger is the parameter $\gamma$. Thus, as Figure 1 shows, $g_{j}^{*}=g_{j}^{t}<g_{j}^{t s}<g_{j}^{s} \cdot 13$

See also that in this model tax and transfer are not interchangeable. The more important transfers are as substitutes for own regional tax, the greater is the divergence of the public good tax-price from the level that would generate the efficient solution at point $A$.

\subsection{Proportional income tax finance}

The same results follow if all the revenue from the private sector has to be obtained with a proportional income tax. Then, the individual's budget constraint is

$$
c_{i j}=y_{i j}-\frac{y_{i j}}{y} s-\frac{y_{i j}}{y_{j}}\left(g_{j}-s_{j}\right),
$$

where $y_{j}=\sum_{i} y_{i j}$ and $y=\sum_{j} y_{j} \cdot\left(y_{i j} / y\right) s$ is the individual's tax liability to the central government to fund the transfer, and $\left(y_{i j} / y_{j}\right)\left(g_{j}-s_{j}\right)$ the individual's liability to the regional government to finance the part of the public good cost not covered by the transfer.

Using (3), the budget constraint can be rewritten as

$$
c_{i j}=y_{i j}\left(1-\gamma \frac{g}{y}\right)-\frac{y_{i j}}{y_{j}}(1-\gamma) g_{j},
$$

or

\footnotetext{
${ }^{13}$ In equilibriums $B$ and $C$, - that is, whenever there are transfers- at the regional and individual levels, income effects may appear. Exclusively in order to provide an unencumbered presentation, in Figure 1 we rule out these income effects, which is equivalent to assuming that $g_{j} / g=N_{j} / N$ when finance is lumpsum, and $g_{j} / g=y_{j} / y$ when it is proportional to income. This allows us to draw equilibriums $B$ and $C$ on the steepest budget line. In both cases, however, and even if the above proportionality results do not hold, the resource constraint is fulfilled, as it should be, at the economy wide level. In the case of own regional taxation, the resource constraint is always fulfilled: not only at the economy wide level, but also at the regional and individual levels.
} 


$$
c_{i j}=y_{i j}\left(1-\gamma \frac{\sum_{k \neq j} g_{k}}{y}\right)-\left[\gamma \frac{y_{i j}}{y}+(1-\gamma) \frac{y_{i j}}{y_{j}}\right] g_{j} .
$$

Expression (9) is the equivalent of expression (4) when the only available tax is proportional to income, and the three scenarios follow from the corresponding values of $\gamma$.

\section{Own regional tax scenario}

If $\gamma=0$, the individual's budget constraint (9) gets reduced to

$$
c_{i j}=y_{i j}\left(1-\frac{g_{j}}{y_{j}}\right) .
$$

The public good is financed by the regional government applying a constant rate $g_{j} / y_{j}$ to individual income $y_{i j}$. In terms of Figure 1, this would be the steepest budget line, with vertical intercept $y_{i j}$ and slope $y_{i j} / y_{j}$.

Thus, individual preferences are given by

$$
w_{i j}=\left(1-\frac{g_{j}}{y_{j}}\right) y_{i j}+H\left(g_{j}\right),
$$

and the level of provision of the public good that maximizes individual utility satisfies the following first order condition:

$$
\frac{d w_{i j}}{d g_{j}}=-\frac{y_{i j}}{y_{j}}+H_{g}\left(g_{j}\right)=0,
$$

or

$$
H_{g}\left(g_{j}\right)=\frac{y_{i j}}{y_{j}}
$$


Under majority rule, the equilibrium level of provision of the public good will be determined by the preferences of the voter with median income, $y_{m j}$. That is,

$$
H_{g}\left(g_{j}^{t}\right)=\frac{y_{m j}}{y_{j}} .
$$

If $y_{i j}$ is symmetrically distributed so that $y_{m j}=\bar{y}_{j}$, where $\bar{y}_{j}$ is the regional mean income, the equilibrium level of provision is also

$$
H_{g}\left(g_{j}^{t}\right)=\frac{\frac{y_{j}}{N_{j}}}{y_{j}}=\frac{1}{N_{j}},
$$

or

$$
N_{j} H_{g}\left(g_{j}^{t}\right)=1, \forall j
$$

If, as assumed, mean income equals median income, the equilibrium level of provision of the public good financed with a regional proportional income tax will be the same as the social optimum level defined in (2). That is, $g_{j}^{t}=g_{j}^{*}$.

This corresponds to point $A$ of Figure 1, although the figure now would only represent the median voter. The vertical intercept of the steepest budget line would now be $y_{m j}$, and the slope $y_{m j} / y_{j}$, which under the assumption that $y_{m j}=\bar{y}$ equals $1 / N_{j}$.

\section{Transfer scenario}

If $\gamma=1$, expression (9) reduces to

$$
c_{i j}=y_{i j}\left(1-\frac{\sum_{k \neq j} g_{k}}{y}\right)-\frac{y_{i j}}{y} g_{j} .
$$

Individual $i$ 's preferences are now

$$
w_{i j}=y_{i j}\left(1-\frac{\sum_{k \neq j} g_{k}}{y}\right)-\frac{y_{i j}}{y} g_{j}+H\left(g_{j}\right) \text {, }
$$

with first order condition 


$$
\frac{d w_{i j}}{d g_{j}}=-\frac{y_{i j}}{y}+H_{g}\left(g_{j}\right)=0,
$$

or

$$
H_{g}\left(g_{j}\right)=\frac{y_{i j}}{y}
$$

In this case, the decisive voter is that with the median level of income over the region. That is,

$$
H_{g}\left(g_{j}^{s}\right)=\frac{y_{m j}}{y}
$$

If median income is equal to mean income, $y_{m j}=\bar{y}_{j}$, the equilibrium level of provision is

$$
H_{g}\left(g_{j}^{s}\right)=\frac{\frac{y_{j}}{N_{j}}}{y}=\frac{y_{j}}{y} \frac{1}{N_{j}},
$$

or

$$
N_{j} H_{g}\left(g_{j}^{s}\right)=\frac{y_{j}}{y}<1, \forall j
$$

Comparing (2) and (11) it follows that $g_{j}^{s}>g_{j}^{*}, \forall j$. Regions over provide the regional public good.

If for region $J$ median income is equal to the country wide average income, $y_{m j}=\bar{y}$, the equilibrium level of public good individually demanded is given by

$$
H_{g}\left(g_{j}^{s}\right)=\frac{\frac{y}{N}}{y}=\frac{1}{N}
$$

Multiplying both sides of the equation by $N_{j}$, this condition can be rewritten as

$$
N_{j} H_{g}\left(g_{j}^{s}\right)=\frac{N_{j}}{N}, \quad \forall j
$$


Since $N_{j} / N<1$, region $j$ over provides the regional public good: $g_{j}^{s}>g_{j}^{*}, \forall j$. See also that expressions (7) and (12) coincide. Thus, if $y_{m j}=\bar{y}$, the equilibrium regional policy will be independent of the type of tax used to fund the transfer; if $y_{m j}>\bar{y}$ the equilibrium provision of the public good will be larger when the transfer is funded with a proportional income tax than when it is funded with a lump-sum tax, and vice versa when $y_{m j}<\bar{y}$.

In terms of Figure 1, equilibrium (12) corresponds, as it was the case with lump-sum finance, with point $C$, only that in this case it only applies to the median voter and the parameters of the budget line are measured differently. The vertical intercept of the flattest budget line would now be $y_{m j}\left[1-\left(\sum_{k \neq j} g_{k} / y\right)\right]$, and the slope $y_{m j} / y$, which under the assumption that $y_{m j}=\bar{y}$ is, as in Figure 1 , equal to $1 / N$.

\section{Tax/transfer mix scenario}

If $0<\gamma<1$, the individual's budget constraint is the same expression (9) and, in this case, the indirect utility function is

$$
w_{i j}=y_{i j}\left(1-\gamma \frac{\sum_{k \neq j} g_{k}}{y}\right)-\left[\gamma \frac{y_{i j}}{y}+(1-\gamma) \frac{y_{i j}}{y_{j}}\right] g_{j}+H\left(g_{j}\right),
$$

with first order condition

$$
H_{g}\left(g_{j}\right)=\gamma \frac{y_{i j}}{y}+(1-\gamma) \frac{y_{i j}}{y_{j}}
$$

In this case, the decisive voter that generates the equilibrium condition is

$$
H_{g}\left(g_{j}\right)=\gamma \frac{y_{m j}}{y}+(1-\gamma) \frac{y_{m j}}{y_{j}}
$$

If within the region median and average income are equal, $y_{m j}=\bar{y}_{j}$, the equilibrium level of provision is 


$$
H_{g}\left(g_{j}^{t s}\right)=\gamma \frac{y_{j}}{y} \frac{1}{N_{j}}+(1-\gamma) \frac{1}{N_{j}},
$$

or

$$
N_{j} H_{g}\left(g_{j}^{t s}\right)=1-\gamma\left(1-\frac{y_{j}}{y}\right), \forall j .
$$

Since $\left(y_{j} / y\right)<1$, condition (13) equates the social marginal benefit to a social marginal cost which is less than 1 , thereby generating an over provision of the regional public good. Further, if $y_{m j}=\bar{y}_{j}=\bar{y}$, the equilibrium level of the public good is

$$
H_{g}\left(g_{j}^{t s}\right)=\gamma \frac{1}{N}+(1-\gamma) \frac{1}{N_{j}}
$$

or

$$
N_{j} H_{g}\left(g_{j}^{t s}\right)=1-\gamma\left(1-\frac{N_{j}}{N}\right), \forall j
$$

which is the same as condition (8). Thus, if $y_{m j}=\bar{y}_{j}=\bar{y}$, the equilibrium provision of the public good will be independent of the type of tax used to fund the transfer; if $y_{m j}>\bar{y}$ the equilibrium provision will be larger when the transfer is funded with a proportional income tax than when it is funded with a lump-sum tax, and vice versa when $y_{m j}<\bar{y}$.

Figure 1 can also handle this equilibrium at point $B$, only that now the middle budget line would have a vertical intercept equal to $y_{m j}\left[1-\gamma\left(\sum_{k \neq j} g_{k} / y\right)\right]$, and a slope equal to $\gamma\left(y_{m j} / y\right)+(1-\gamma)\left(y_{m j} / y_{j}\right)$, which under the assumptions held about the distribution of income reduces to $\gamma(1 / N)+(1-\gamma)\left(1 / N_{j}\right)$, exactly the same as that depicted in Figure 1.

\subsection{Summary of results}

Figure 2 shows, in the demand/supply space, the level of provision of the regional public good of each scenario. The reference case is the Pareto efficient equilibrium, 
where the regional public good, $g_{j}^{*}$, is provided up to the point where aggregate demand, the sum over all regional residents of the marginal rates of substitution between the public good and private consumption -we call this concept the sum of marginal benefits, $\sum_{i} M B_{i j}$ - equals aggregate supply, the total marginal cost of provision, $\sum_{i} M C_{i}$, which under the assumptions of our model is equal to 1 .

The equilibrium level of provision coincides with the Pareto efficient equilibrium in the case of own regional tax finance, $g_{j}^{t}$-conditions (6) and (10). There is however over provision in the case of the tax/transfer mix scenario, $g_{j}^{t s}$-conditions (8) and (14) - and in the transfer scenario, $g_{j}^{s}$-conditions (7) and (12). Also, the degree of over provision increases as we go from the own tax scenario to the transfer scenario. Given that $\left(N_{j} / N\right)<1$, it must be the case that $g_{j}^{*}=g_{j}^{t}<g_{j}^{t s}<g_{j}^{s} .{ }^{14}$

\section{Figure 2: Comparison of alternative regional finance scenarios}

\footnotetext{
${ }^{14}$ The results of Section 3 are all obtained under the assumption of non distortionary taxation. It is therefore pertinent to ask to what extent they would change should the recourse to this type of taxes be not available. This opens a wide area of analysis (see for instance Dahlby, 2008) which would take us far away from the purpose of this article. We nevertheless present in the Annex to this work a simple extension of the tax/transfer mix model used here that takes into account the efficiency cost of taxation. Using a representative individual assumption, and therefore abstracting from distributional considerations, we show that the qualitative results obtained above are maintained when taxes affect negatively the level of individual income.
} 


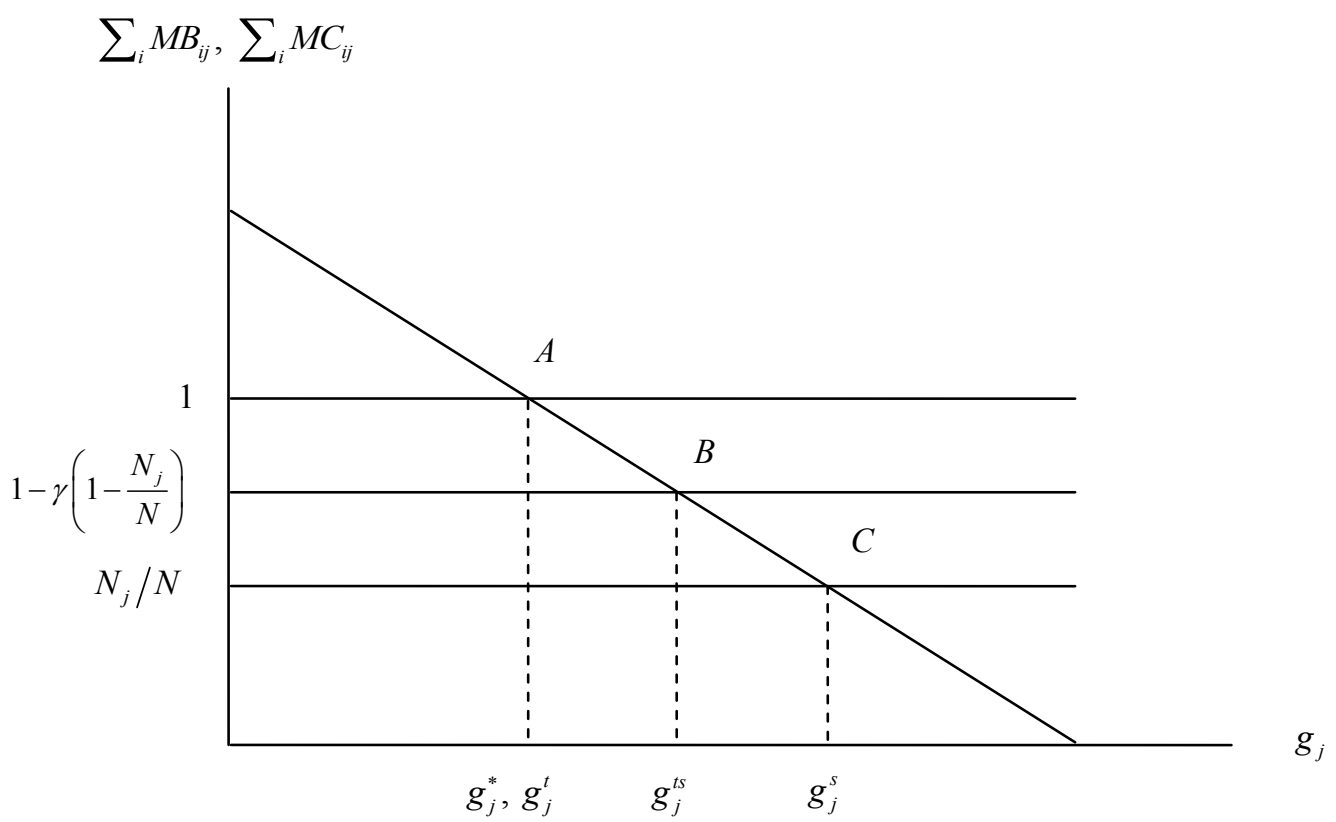

\section{Exogenous transfer finance}

Notice that in the above model, the transfer is defined as a given fraction $\gamma$ of the equilibrium provision level of the regional public good. If the transfer is assumed to be completely independent of the level of provision of the regional public good, then results are quite different from those obtained in the mix tax/transfer scenario of Section 3. In particular, the determining element is then again the marginal own tax and, under certain conditions, full Pareto efficient results are obtained.

Both models capture some elements of reality, and both are abstractions that miss particular features of actual finance systems. For instance, in the model of Section 3 we have assumed that the parameter $\gamma$ is the same for all regions, while a regional specific parameter may be more realistic. On the other hand, the complete exogeneity of the transfer is difficult to defend in the light of the equalising nature that these transfers use to present in real finance systems. In any case, and for the purpose of completeness, we develop in this section a tax/transfer scenario with the transfer exogenously determined. 
Consider a system in which the exogenously determined fixed transfer to region $j$, $s_{j}$, does not cover the whole of the cost of the public good. That is, $s_{j}<g_{j}{ }^{15}$ As in Section 3, we consider both lump-sum and proportional income taxation to finance this transfer and the rest of the public expenditure.

\subsection{Lump-sum taxation}

Suppose that to finance all the $s_{j}$ 's transfers the central government collects from the whole country's population a lump sum tax equal to $(1 / N) s$, where $s=\sum_{j} s_{j}$. Since $s_{j}<g_{j}, \forall j$, region $j$ additionally collects a lump-sum tax to finance the uncovered part of the cost of the public good equal to $\left(1 / N_{j}\right)\left(g_{j}-s_{j}\right)$. The individual's preferences are now:

$$
w_{i j}=y_{i j}-\frac{1}{N} s-\frac{1}{N_{j}}\left(g_{j}-s_{j}\right)+H\left(g_{j}\right)
$$

and the demanded level of public good will satisfy the first order condition

$$
\frac{d w_{i j}}{d g_{j}}=-\frac{1}{N_{j}}+H_{g}\left(g_{j}\right)=0,
$$

or

$$
N_{j} H_{g}\left(g_{j}^{t(e) s}\right)=1
$$

where $g_{j}^{t(e) s}$ is the equilibrium level of provision of the public good when the exogenous transfer is complemented in the margin with own regional taxation. This structure of finance, therefore, does effectively generate the provision of the efficient level of the public good, $g_{j}^{t(e) s}=g_{j}^{*}$.

However, despite the fact that expression (15) is the same as expression (6), the present tax/transfer equilibrium is not in general the same as that discussed in Section 3. The individual's budget constraint in this case is

\footnotetext{
${ }^{15}$ In principle, $s_{j}$ could be greater than $g_{j}$, but then the regional tax would be negative. That is, the regional government would give a hand out to the residents of that region.
} 


$$
c_{i j}=y_{i j}-\left(\frac{s}{N}-\frac{s_{j}}{N_{j}}\right)-\frac{1}{N_{j}} g_{j} .
$$

That is, the tax/transfer scenario leaves the tax-price of the public good unchanged, but introduces in general an income effect, the sign of which, as Figure 3 shows, depends on how the transfer is distributed among regions. This circumstance has no effect on the demand of the public good if, as is the case in our model, preferences are quasi-linear. With this utility function, the income effect on the public good is zero, all pure variations in income being absorbed by the consumption of the private good. But for a more general utility function, a pure variation in income would change the consumption of both private and public goods.

\section{Figure 3: Tax/(exogenous) transfer mix and quasi-linear preferences}

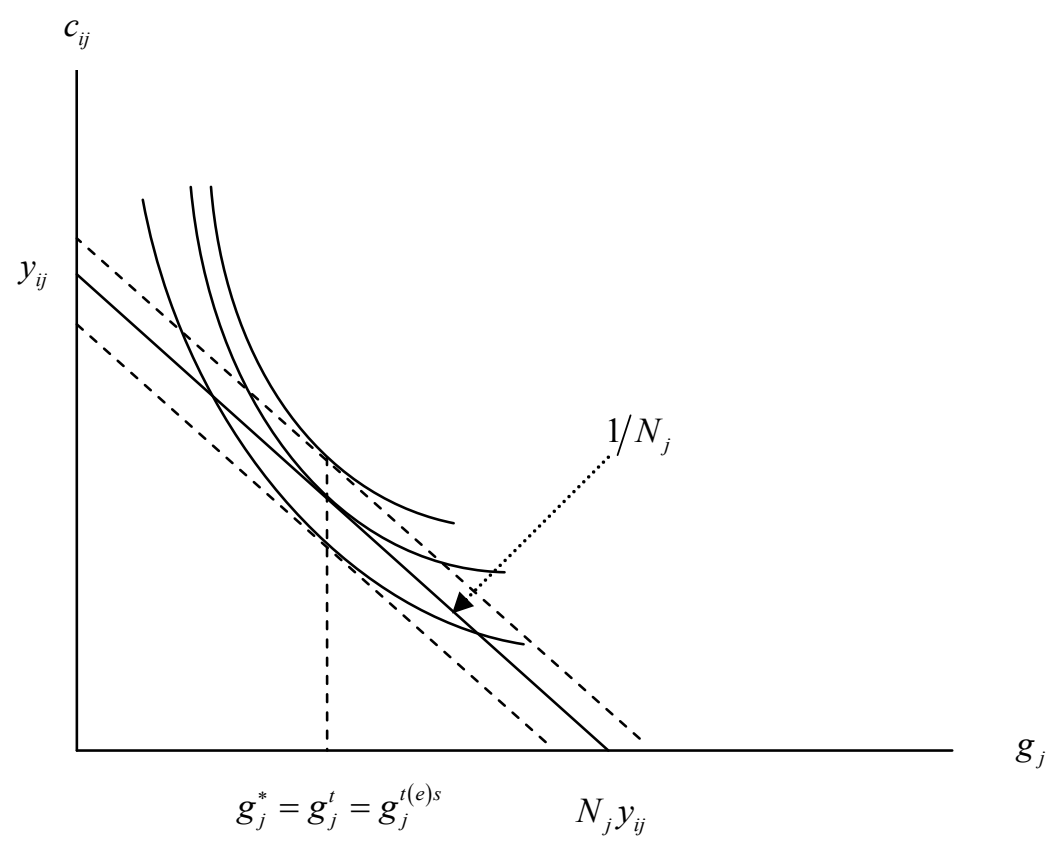

This raises some interesting questions regarding both the design of the transfer system and the equivalence between the tax and the tax/transfer scenarios. Even if preferences are quasi-linear, the equivalence between the tax and tax/transfer equilibriums will only refer to the provision of the public good, but not to the consumption of the private good. If preferences are not quasi-linear, there will be no equivalence in the consumption of either private or public good. Perfect equivalence between the two scenarios only holds when the total transfer is distributed among 
regions according to relative population, $s_{j}=\left(N_{j} / N\right) s$. In that case, the income effect disappears and the budget line of all regions is exactly the same as the one considered in Section 3.1 for the own regional tax scenario; that is, the continuous budget line of Figure 3. If the total transfer is not distributed according to relative population, there will be regions in which the income effect will be positive -those for which $s_{j}>\left(N_{j} / N\right)$, represented in the figure by the upper dotted budget line- and others in which it ill be negative -those for which $s_{j}<\left(N_{j} / N\right)$, represented by the lower dotted budget line.

\subsection{Proportional income taxation}

Suppose now that both central and regional governments finance, respectively, the transfer and the uncovered gap with a proportional income tax. Then the individual's indirect utility function is:

$$
w_{i j}=y_{i j}-\frac{y_{i j}}{y} s-\frac{y_{i j}}{y_{j}}\left(g_{j}-s_{j}\right)+H\left(g_{j}\right)
$$

The first order condition is

$$
\frac{d w_{i j}}{d g_{j}}=-\frac{y_{i j}}{y_{j}}+H_{g}\left(g_{j}\right)=0
$$

or

$$
H_{g}\left(g_{j}\right)=\frac{y_{i j}}{y_{j}}
$$

and, under majority rule, if $y_{m j}=\bar{y}_{j}$, the equilibrium level of provision of the public good in this case is

$$
N_{j} H_{g}\left(g_{j}^{t(e) s}\right)=1, \forall j
$$

Again the mix tax/transfer is efficient, $g_{j}^{t(e) s}=g_{j}^{*}$.

Figure 3 also represents this median voter equilibrium but then the vertical intercept of the budget line is $y_{m j}\left[1-(s / y)+\left(s_{j} / y_{j}\right)\right]$, and the slope $y_{m j} / y_{j}$, which for the 
assumptions used above equals $1 / N_{j}$. Now, the tax and tax/transfer scenarios are fully equivalent when the transfer is distributed among regions according to relative income, $s_{j}=\left(y_{j} / y\right) s$. Only in that case does the income effect cease to exist and for all regions the relevant budget is the continuous line of Figure 3.

\section{Other scenarios of interest}

Sections 3 and 4 do not exhaust the possible scenarios of interest, although the remaining ones can be shown to be identical to the alternatives that we have already considered in this paper, albeit with some changes in nomenclature. Again for completeness, we make in this section some brief considerations on these other scenarios.

\subsection{Tax revenue sharing}

Sharing the revenue raised by a central tax in order to finance the provision of a regional public good is the same as using transfer finance. Suppose the central government collects a nation-wide proportional income tax to finance both its own national public good and all the regional public goods. If region $j$ shares on this revenue so that its public good $g_{j}$ can be financed, the individual share cannot be other than $\left(y_{i j} / y\right) g$. But this is equivalent to the case of a transfer financed with a proportional income tax, and therefore the demand of the regional public good must be (12). And the same is true if instead of a proportional income tax, a lump sum tax is considered. Then the individual share needed to finance the regional public good would be $(1 / N) g$ and the demand for the public good would be given by (7), the one corresponding to a transfer financed with a lump-sum tax.

Tax sharing has been advocated as a form of participation by regions in potentially large tax bases, in which the central government has a larger comparative advantage in efficient exploitation than regions. Apart from this, perhaps the only other advantage that tax revenue share has over transfers is that individuals may be more aware of what 
it is that they are really financing with their taxes, and thus make more unlikely the incidence of the phenomenon of fiscal illusion that we discuss below. ${ }^{16}$

\subsection{Own taxes/shared taxes finance}

The tax/transfer mix results are immediately applicable to a scenario in which own taxes complement not an exogenous transfer from the central government, but an exogenously fixed share of the central tax. It is easy to show that in this scenario the Pareto efficient equilibrium can also be reached, whether taxes are lump-sum or proportional to income.

This is a widely used structure in practice. For instance, the Spanish regional finance system combines the three types of revenue considered in this paper. In addition to transfers, Spanish autonomous communities have the revenue obtained from a set of ceded taxes. Some of these are real own regional taxes in that autonomous communities can decide, subject to certain restrictions, tax rates and some elements of the taxable base; this is the case, for instance, of the personal income tax and the inheritance tax. Other ceded figures fall squarely into the category of tax-sharing, as communities receive the revenue raised in their territory but have no responsibility whatsoever in establishing the corresponding tax liability: this is the case of VAT and excises. ${ }^{17}$

\section{Fiscal illusion}

Fiscal illusion has frequently been associated with the so called "flypaper effect". If this is defined as the increase in public good provision resulting from the substitution of transfers for own regional taxes, then, as can be seen in Section 3, our model yields this effect with no need to appeal to the existence of "fiscal illusion" by the part of the individual. In our model, which is resource constrained, the equivalence Bradford and

\footnotetext{
${ }^{16}$ Spanish experience on the effect of tax revenue sharing on the perception of regional taxpayers is not very encouraging. Surveys systematically show that a significant percentage of people is not capable of correctly identifying the level of government responsible for major taxes and public services. See, for instance, Área de Sociología Tributaria (2011) and López-Laborda and Rodrigo (2012).

${ }^{17}$ See Zabalza and López-Laborda (2011).
} 
Oates (1971) result does not apply: transfers and own regional taxes are not interchangeable as far as their effect on the demand of the public good. We nevertheless think that in federal finance "fiscal illusion" may play a role important enough to merit attention, and therefore consider in this section what the consequences of this phenomenon would be for the three scenarios contemplated in Section 3. ${ }^{18}$

\subsection{Tax/transfer mix scenarios with fiscal illusion}

The continuum of scenarios examined above assumes a high level of fiscal perception by the part of the individual. Among the taxes paid to the central government, one is able to differentiate between that levied to fund the transfer to the regions and that levied to finance the national public good. This, however, may no be the case. The individual may suffer from "fiscal illusion" and fail to distinguish between the two types of tax paid to the central government and, therefore, fail as well to see the link between any of these taxes and the level of public good.

If $\gamma=0$, there is no possibility of confusion as the individual pays only one tax to the central government; namely, concentrating our explanation only on lump-sum tax case, ${ }^{19}$ the tax destined to finance the national public good $g_{c} / N$, which is already incorporated in the term $y_{i j}$. The other tax paid, $g_{j} / N_{j}$, is collected by the regional government, and thus, according to our definition of fiscal illusion, does not generate any misperception. The budget constraint is still limited by the steeper line in Figure 1 and therefore nothing changes as far as the equilibrium is concerned. In terms of our model, the own taxation scenario is not compatible with fiscal illusion.

If $0<\gamma<1$, the overall tax revenue collected from the individual by the central government is composed of that coming from the tax destined to finance the national

\footnotetext{
18 The "flypaper effect" is defined as the differential effect that transfers have on regional public good provision as compared with the response elicited by increases in disposable income. According to Hines and Thaler (1995), Arthur Okun coined the label because the money that the central government sends to the regions "sticks where it hits". The first pieces of empirical evidence on the existence of the flypaper effect are due to Henderson (1968) and Gramlich (1969). For a review of the wide theoretical and empirical literature on this effect see Bailey (1999, ch. 11) and Gamkhar and Shah (2007). As Hines and Thaler (1995) point out in their survey, there have been two general strands of enquiry to explain this effect. One is based on the behavior of bureaucrats interested in maximizing the size of their department's budget, and the other on the existence of some sort of misperception ("fiscal illusion") by the part of individuals.

${ }^{19}$ The effect of fiscal illusion is the same whether we consider lump-sum or income proportional taxation.
} 
public good, $g_{c} / N$ plus that coming from the tax destined to finance the transfer to the regions, $\gamma\left(\sum_{j} g_{j} / N\right)$. Thus the budget constraint that the individual perceives is

$$
c_{i j}=y_{i j}^{\prime}-\frac{1-\gamma}{N_{j}} g_{j},
$$

where

$$
y_{i j}^{\prime}=m_{i j}-\frac{1}{N}\left(g_{c}+\gamma \sum_{j} g_{j}\right)
$$

The individual obviously knows what the amount of tax exacted from him by the central government is, namely $(1 / N)\left(g_{c}+\gamma \sum_{j} g_{j}\right)$, but because of fiscal illusion, he cannot distinguish between $g_{c}$ and $\gamma \sum_{j} g_{j}$, nor therefore see the link between the regional public good and the compensatory transfer received by the regional government. The whole of $y_{i j}^{\prime}$ is thus perceived as an exogenous variable unrelated to the provision of the regional public good, and the first order condition that the demanded level of the regional good, $g_{j}^{t s(f i)}$, will have to satisfy is

$$
\frac{d w_{i j}}{d g_{j}}=-\frac{(1-\gamma)}{N_{j}}+H_{g}\left(g_{j}^{t s(f i)}\right)=0
$$

or

$$
N_{j} H_{g}\left(g_{j}^{t s(f i)}\right)=1-\gamma, \forall j
$$

The perceived social marginal cost is less with than without fiscal illusion as

$$
1-\gamma<1-\gamma\left(1-\frac{N_{j}}{N}\right)
$$

Therefore, fiscal illusion worsens the distortion of compensatory transfers and thus the over provision of the regional public good: $g_{j}^{t s(f i)}>g_{j}^{t s} \cdot{ }^{20}$

\footnotetext{
${ }^{20}$ Oates (1979) advances a model of "fiscal illusion" that is closely related to the one presented here but not identical. First, he adopts a partial equilibrium approach because he ignores the funding of the central government transfer. Second, Oates' particular definition of fiscal illusion involves individuals confusing the average and marginal tax-price of the public good. Our definition, on the other hand, relies only on the
} 
Finally, if $\gamma=1$, the possibility of confusion by the part of the individual is at a maximum. The perceived budget constraint in this case is

$$
c_{i j}=y_{i j}^{\prime \prime},
$$

where

$$
y_{i j}^{\prime \prime}=m_{i j}-\frac{1}{N}\left(g_{c}+\sum_{j} g_{j}\right) \text {. }
$$

The budget line becomes horizontal, and equilibrium is reached at a point of tangency with the corresponding indifference curve where both the marginal rate of substitution is zero and the resource constraint is satisfied. The level of provision of the regional public good, $g_{j}^{s(f i)}$, satisfies then the condition

$$
N_{j} H_{g}\left(g_{j}^{s(f i)}\right)=0, \quad \forall j
$$

and $g_{j}^{s(f i)}>g_{j}^{s}$. Individuals internalize the benefits of the regional public good, but erroneously perceive that it has a zero tax-price.

This is obviously an extreme and unlikely occurrence, which should make us reflect on the nature of the fiscal illusion assumption. This result would lead to a large demand of the public good but, and this is important to note, also to a too small, perhaps unsustainable amount of private consumption. ${ }^{21}$ The illusion-distorted marginal tax price is the signal that compels the consumer to demand that much public good, but the opposite effect on private consumption caused by the scarcity of resources is a reminder to the same consumer that something may be wrong with his perception as to what is the true tax-price of the public good. Fiscal illusion may be real enough in situations in which economic agents have to deal with several interrelated government levels, but this argument suggests that it must necessarily be a local phenomenon. Fiscal illusion

inability to distinguish the use of taxes when the taxing government uses more than one tax and is, in some sense, more removed from the taxpayer than the regional government. See also Courant, Gramlich and Rubinfeld (1979). They use the same definition of fiscal illusion as Oates, but take into account the funding of the central government transfer.

${ }^{21}$ In a more general model it could also lead to a sub optimal consumption of the national public good: See Logan (1986). 
cannot persist for large changes; it must correct itself as the consequences of large changes are born by the consumer. ${ }^{22}$

\subsection{The empirical relevance of "fiscal illusion": some illustrative calculations}

Figure 4 shows the effect of fiscal illusion in the tax/transfer mix scenario. In this case, equilibrium with fiscal illusion is at point $B^{\prime}$, with a larger level of provision of the public good than would be the case without fiscal illusion.

The increase in the public good depends on the elasticity of demand for the public good with respect to social marginal cost. Let us suppose for simplicity that this elasticity is constant over the relevant range and equal to $\varepsilon_{g c}$, then the relative change in the level of provision of the public good, $d g_{j} / g_{j}$, is

$$
\frac{d g_{j}}{g_{j}}=\frac{d M C}{M C} \varepsilon_{g c} .
$$

On the other hand, from (14) and (18)

$$
\frac{d M C}{M C}=-\frac{\gamma\left(N_{j} / N\right)}{1-\gamma\left[1-\left(N_{j} / N\right)\right]} .
$$

Therefore,

$$
\frac{d g_{j}}{g_{j}}=-\frac{\gamma\left(N_{j} / N\right)}{1-\gamma\left[1-\left(N_{j} / N\right)\right]} \varepsilon_{g c} .
$$

The fraction on the right hand side of (19) is positive $[0: 1]$ and increasing in coverage factor and region size. Thus, since $\varepsilon_{g c}<0, d g_{j} / g_{j}>0$.

\section{Figure 4: The effect of fiscal illusion}

\footnotetext{
${ }^{22}$ See also that in this argument, the general equilibrium nature of the model plays an important role. We are essentially dealing with substitution effects. Income effects, when present, are very small. Thus, when testing empirically the presence of fiscal illusion, demand responses should be estimated holding real income constant.
} 


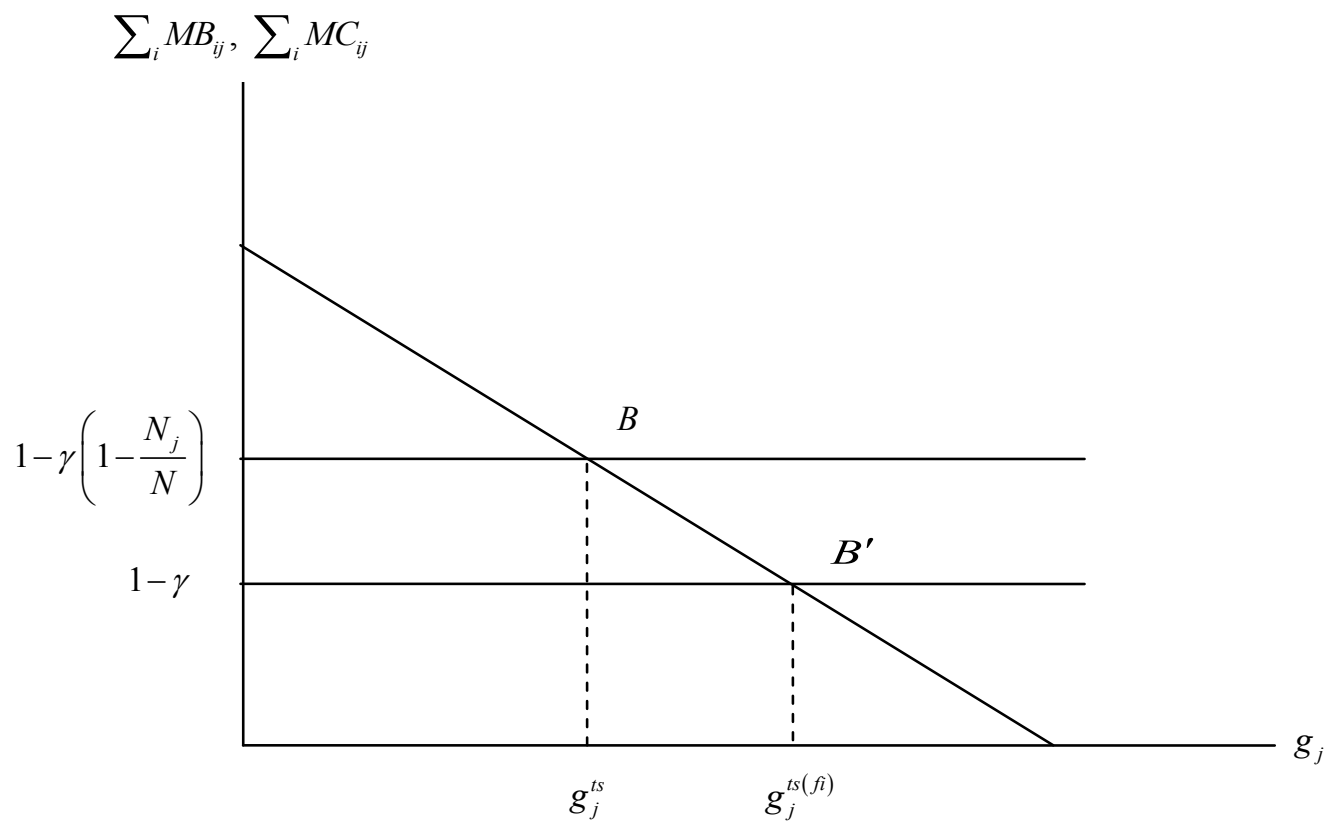

What we want to ascertain is whether the responsiveness of public expenditure with respect to transfers increases with fiscal illusion. In our model, an increase in $\gamma$ measures by definition a substitution of transfers for own regional taxes. Without fiscal illusion, the elasticity of public expenditure with respect to $\gamma, \varepsilon_{g \gamma}$, is

$$
\varepsilon_{g \gamma}=-\frac{\gamma\left[1-\left(N_{j} / N\right)\right]}{1-\gamma\left[1-\left(N_{j} / N\right)\right]} \varepsilon_{g c} .
$$

Whereas with fiscal illusion, this elasticity is

$$
\varepsilon_{g \gamma}^{f_{i}}=-\frac{\gamma}{1-\gamma} \varepsilon_{g c}
$$

Therefore, the differential response of public good provision on transfer increase due to fiscal illusion is

$$
\varepsilon_{g \gamma}^{f i}-\varepsilon_{g \gamma}=-\frac{\gamma\left(N_{j} / N\right)}{(1-\gamma)\left\{1-\gamma\left[1-\left(N_{j} / N\right)\right]\right\}} \varepsilon_{g c}
$$

or, using (19), 


$$
\varepsilon_{g \gamma}^{f i}-\varepsilon_{g \gamma}=\frac{1}{1-\gamma} \frac{d g_{j}}{g_{j}} .
$$

Table 1 presents, in percentage terms, values for expressions (20), (21) and (22) for an assumed demand elasticity of -0.5 and different values of $\gamma$ and $N_{j} / N$.

Table 2: The effect of fiscal illusion

\begin{tabular}{|c|c|c|c|}
\hline & \multicolumn{3}{|c|}{$\varepsilon_{g c}=-0.5$} \\
\hline \multirow[b]{2}{*}{$\gamma$} & \multicolumn{3}{|c|}{$N_{j} / N$} \\
\hline & 0.05 & 0.10 & 0.20 \\
\hline & \multicolumn{3}{|c|}{$\varepsilon_{g \gamma}$} \\
\hline 0.3 & 0.20 & 0.18 & 0.16 \\
\hline 0.5 & 0.45 & 0.41 & 0.33 \\
\hline \multirow[t]{2}{*}{0.7} & 0.99 & 0.85 & 0.64 \\
\hline & \multicolumn{3}{|c|}{$\varepsilon_{g \gamma}^{f i}$} \\
\hline 0.3 & 0.21 & 0.21 & 0.21 \\
\hline 0.5 & 0.50 & 0.50 & 0.50 \\
\hline \multirow[t]{2}{*}{0.7} & 1.17 & 1.17 & 1.17 \\
\hline & \multicolumn{3}{|c|}{$\varepsilon_{g \gamma}^{f i}-\varepsilon_{g \gamma}:$ Differential effec } \\
\hline 0.3 & 0.01 & 0.03 & 0.06 \\
\hline 0.5 & 0.05 & 0.09 & 0.17 \\
\hline 0.7 & 0.17 & 0.32 & 0.53 \\
\hline
\end{tabular}

These are illustrative calculations, but fall within the range of empirically estimated effects (Fisher, 1982), particularly if we take into account that they refer, as we believe it should be, to resource compensated effects. From the second panel, it is clear that the existence of fiscal illusion generates a demand response that increases with the size of the transfer but is unaffected by region size. This is a potentially testable hypothesis to ascertain the existence of fiscal illusion since, as can be observed in the first panel, without fiscal illusion the demand response, although it also increases with respect to transfer size, it decreases with the size of the region. Indeed, this is precisely what expressions (20) and (21) suggest: a) Without fiscal illusion, the responsiveness of demand for the regional public good with respect to transfers depends on both the fraction that the transfer represents of total public expenditure and the relative size of 
the region. And b) with fiscal illusion, the responsiveness of demand for the regional public good with respect to transfers depends only on the fraction that the transfer represents of total public expenditure.

In the context of our model, we can also be more precise as to the relationship between transfer elasticity, region and transfer size. Figure 5, which is based on expression (20), shows how, holding constant the relative size of the region, the elasticity without fiscal illusion increases very slowly if the transfer is relatively small, but very fast as the transfer becomes larger and larger. Also, for a given coverage fraction of the transfer, the larger is the region the smaller should the elasticity be. In short, without money illusion these two variables - region and transfer size - interact with each other in a multiplicative fashion. This is again a testable proposition.

Figure 5: The influence of transfer and region size on elasticity

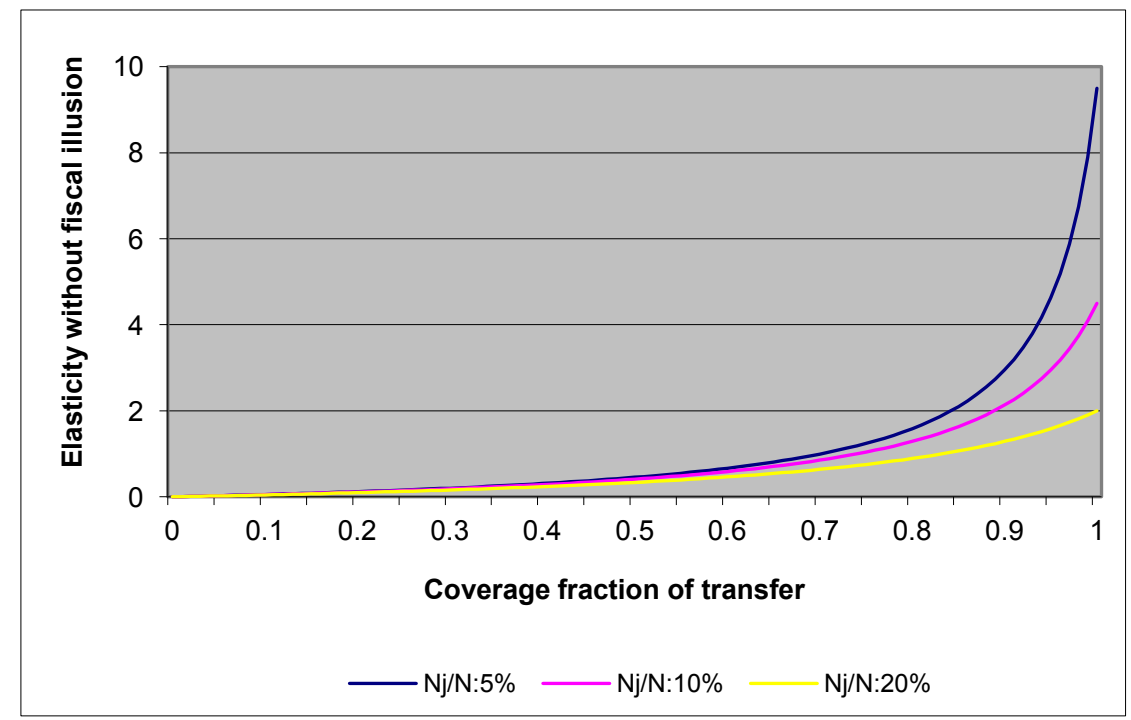

\subsection{Fiscal illusion and the tax/exogenous transfer mix scenario}

For the same reasons discussed with respect to the own regional tax scenario, the mix scenario with an exogenous transfer complemented with a regional tax, considered in Section 4, is not compatible with money illusion. In that scenario the transfer exerts a mere income effect. Therefore, confusing the destination of the two taxes paid by the individual to the central government has no effect on the tax price of the public good. The equilibrium with fiscal illusion is the same as that without fiscal illusion discussed above. 
Things would be different, of course, if the definition of fiscal illusion given above in Section 6.1 was enlarged to include, not only the failure by the part of the individual to distinguish between the two taxes paid to the central government, but also the mistaken perception of considering the exogenous transfer linked to the provision of the regional public good. But this would lead us to an analysis identical to the case considered in Section 6.2, and at the cost of lowering significantly the explanatory power of our definition of fiscal illusion. We thus prefer to leave this definition free of additional elements that belong more properly to the institutional setting of the system of finance than to the sphere of individual perceptions.

\section{Concluding remarks}

The purpose of this paper has been to evaluate in terms of efficiency the most relevant finance scenarios open to regional governments. In particular, we have considered the following alternative forms of regional finance: own regional taxes; transfers from the central government; and transfers complemented with own regional taxes.

The model used to evaluate these different scenarios is based on individual demand decisions concerning the level of the regional public good, where individuals have identical quasi-linear preferences defined over private consumption and the regional public good, and where only endowment income varies between individuals and regions. This is admittedly a very simple model, but we show that it is sufficient to discriminate between the efficiency properties of the different scenarios considered.

The equilibrium level of provision coincides with the Pareto efficient equilibrium in the case of own regional tax finance, but there is over provision if there is a transfer from the central government that is a given fraction of the cost of the demanded public good. We show that the degree of over provision increases as the coverage fraction of the transfer increases. If, on the other hand, the transfer is independent of the level of provision of the public good, efficiency is re-established providing that this transfer is marginally complemented with an own regional tax. Although the basic model from which these results are obtained assumes non distortionary taxation, we argue in the Appendix that these results are likely to hold also in a situation in which taxes have efficiency costs. 
We use this model to define formally the concept of fiscal illusion as the failure by the part of the individual to distinguish between the different taxes he pays the central government, and therefore the different types of expenditure they finance. We show that the own regional tax scenario is not compatible with fiscal illusion as defined here, whereas the tax/transfer scenario yields a higher demand for the public good with than without fiscal illusion. The model suggests two hypotheses, both of them potentially testable, according to which without fiscal illusion, the responsiveness of demand for the regional public good with respect to transfers depends on the relative size of both the transfer (in a positive way) and the region (in a negative way), whereas with fiscal illusion the responsiveness of demand for the regional public good depends only (positively) on the fraction that the transfer represents of total public expenditure. We also argue that fiscal illusion must necessarily be a local phenomenon, which is likely to correct itself when the consumer becomes aware of the global implications (namely, the cost in terms of lost private consumption) of misperceiving the tax-price of public goods.

McLure (1983) is right when he reminds us of the differences between theoretical recommendations and the real world. The distribution of resources between different levels of government does not take place in a void. There are many historical, political, geographic and cultural factors that end up playing a significant role in determining the distribution of tax responsibilities assigned to subcentral governments. The weight of own taxes in regional governments will not be the same in a country in which decentralization has proceeded from top to bottom, than in another were the process has been the other way around. Still, we feel that theoretical analysis, such as the one developed here, may help us not only to understand the essential elements of the problem at hand, but also, by enabling us to identify the cost of suboptimal financial configurations, to gain an idea of the importance that economic agents place on these other historical and cultural factors.

\section{Annex}

A tax/transfer mix model with distortionary income taxation 
How would the results of Section 3 above be altered if we consider distortionary taxation? The answer is "not much" if, keeping in the line of maximum simplicity adopted in this article, we abstract from distributional considerations.

Let us suppose that we have an economy of identical individuals, all with the same level of income $y^{i}$. They live in $J$ territorial jurisdictions, populated with $N_{j}$ inhabitants $(j=1, \ldots, J)$. That is, we have an economy with $J$ identical representative consumers, each living in a jurisdiction of different predetermined size. Taxation imposes an efficiency cost: the higher the rate of taxation $t_{j}$ is, the lower the level of individual income will be. This effect is the same for all individuals. Other than these, all the assumptions used in the main text are maintained here.

We start with equation (9), which given the new assumptions and notation reads:

$$
c^{i}=y^{i}\left(1-\gamma \sum_{k \neq j} t_{k} f_{k}\right)-\left[\gamma \frac{y^{i}}{y}+(1-\gamma) \frac{y^{i}}{y_{j}}\right] t_{j} y_{j},
$$

where $t_{j}=g_{j} / y_{j}, \forall j, y_{j}=N_{j} y^{i}, f_{k}=y_{k} / y, y=N y^{i}$ and $N=\sum_{j} N_{j}$.

Substituting (A.1) into (1), the representative individual's indirect utility function is

$$
W^{i}=y^{i}\left(1-\gamma \sum_{k \neq j} t_{k} f_{k}\right)-\left[\gamma \frac{y^{i}}{y}+(1-\gamma) \frac{y^{i}}{y_{j}}\right] t_{j} y_{j}+H\left(t_{j} y_{j}\right),
$$

and, assuming no cross tax effects between regions, the first order condition for the tax rate that maximises welfare

$$
\frac{\delta W^{i}}{\delta t_{j}}=\left(1-\gamma \sum_{k} t_{k} f_{k}\right) \eta \frac{y^{i}}{t_{j}}-\left[\gamma \frac{1}{N}+(1-\gamma) \frac{1}{N_{j}}\right] y_{j}(1+\eta)+H_{g} y_{j}(1+\eta)=0 .
$$

or,

$$
N_{j} H_{g}\left(g_{j}\right)=1-\gamma\left(1-\frac{N_{j}}{N}\right)-\left(1-\gamma \sum_{k} t_{k} f_{k}\right) \frac{\eta}{t_{j}(1+\eta)},
$$

where $\eta$ is the elasticity of personal income with respect to the income tax rate,

$$
\eta=\frac{\delta y^{i}}{\delta t_{j}} \frac{t_{j}}{y^{i}}
$$


which following Dahlby (2008) we assume to hold constant over the relevant range of analysis. We further assume that $\eta<0$ and, to ensure that a change in the tax rate increases revenue, that $|\eta|<1$.

Given these assumptions, to see the difference that distortionary taxation makes with respect to the optimal allocation, expression (A.3) must be compared with expression (8). The new term that appears in the first order condition is

$$
-\left(1-\gamma \sum_{k} t_{k} f_{k}\right) \frac{\eta}{t_{j}(1+\eta)}
$$

which is positive. With distortionary taxation, the sum of marginal benefits has to be equated to an aggregate marginal cost $\left(M C^{d}\right)$ that is higher than the one associated to lump sum taxation $\left(M C^{l s}\right)$. Other things equal, the more distortionary the tax is, the larger the difference between $M C^{d}$ and $M C^{l s}$. Thus, with distortionary taxation, the level of provision of the public good is lower than the level associated to lump sum taxation.

Expression (A.3) is the general case, where $\gamma(0<\gamma<1)$ measures the tax/transfer mix. If $\gamma=0$, the provision of the regional public goods is financed only with own regional taxes. In that case, we have from (A.3) that

$$
N_{j} H_{g}\left(g_{j}\right)=1-\frac{\eta}{t_{j}(1+\eta)}
$$

This is greater than 1 , the value of the aggregate marginal cost with lump sum finance case - see expression (6) above. Again, with respect to the lump sum finance case, the provision of the regional public good is reduced.

Finally, if $\gamma=1$, the regional public good is financed only with transfers, and the condition becomes

$$
N_{j} H_{g}\left(g_{j}\right)=\frac{N_{j}}{N}-\left(1-\sum_{k} t_{k} f_{k}\right) \frac{\eta}{t_{j}(1+\eta)},
$$

which is greater than $N_{j} / N$, the marginal cost with lump sum finance - see expression (7) above- and thus yields again a lower level of provision of the regional public good. 
It is easy to show that the marginal cost associated to these three expressions, keeps the same ordering as that found in the lump sum finance case. In particular, partially differentiating the right hand side of (A.3) with respect to $\gamma$ we find that the marginal cost decreases as the transfer represents a higher proportion of total finance:

$$
\frac{\delta M C^{d}}{\delta \gamma}=-\left(1-\frac{N_{j}}{N}\right)+\sum_{k \neq j} t_{k} f_{k} \frac{\eta}{t_{j}(1+\eta)}<0 .
$$

Therefore, the result that the provision of the public good increases as we substitute transfers for own regional taxation is maintained with distortionary taxation. In this case, however, we cannot assert that the all tax equilibrium $(\gamma=0)$ coincides with the Pareto efficient equilibrium, as it was the case with lump sum finance.

\section{References}

[1] ÁREA DE SOCIOLOGÍA TRIBUTARIA (2011): "Opiniones y actitudes fiscales de los españoles en 2010", Documentos No 09/11, Madrid: Instituto de Estudios Fiscales.

[2] BAILEY, S. J. (1999): Local Government Economics. Principles and Practice, London: MacMillan.

[3] BOADWAY, R. (2012): "International Lessons in Fiscal Federalism Design", eJournal of Tax Research, 10 (1): 21-48.

(http://www.asb.unsw.edu.au/research/publications/ejournaloftaxresearch/Docu ments/paper3_v10n1_Boadway.pdf)

[4] BOADWAY, R. and A. SHAH (2009): Fiscal Federalism. Principles and Practice of Multiorder Governance, New York: Cambridge University Press.

[5] BOWEN, H. R. (1943): "The interpretation of voting in the allocation of resources", Quarterly Journal of Economics, 58: 27-48.

[6] BIRD, R. M. (1993): "Threading the fiscal labyrinth: Some issues in fiscal decentralization", National Tax Journal, 46 (2): 207-227.

[7] BRADFORD, D. F. and W. E. OATES (1971): "The analysis of revenue sharing in a new approach to collective fiscal decisions", Quarterly Journal of Economics, 85: 416-439.

[8] BRENNAN, G. and J.M. BUCHANAN (1983): "Normative tax theory for a federal polity: some public choice preliminaries", in Ch. E. McLURE, ed.: Tax assignment in federal countries, Canberra: Centre for Research on Federal Financial Relations, The Australian National University, pp.52-65.

[9] BUCHANAN, J. M. (1950):"Federalism and fiscal equity", American Economic Review, 40 (4): 583-599. 
[10] CASAHUGA, A. (1982): "La invalidez general del teorema de la descentralización”, Cuadernos Económicos del ICE, 20: 37-51.

[11] COURANT, P. N., E. M. GRAMLICH and D. L. RUBINFELD (1972): "The stimulative effects of intergovernmental grants: or why money sticks where it hits", in P. MIESZKOWSKI and W.H. OAKLAND (eds.): Fiscal Federalism and Grants-in-Aid, Washington: The Urban Institute.

[12] DAHLBY, B. (2008): The Marginal Cost of Public Funds. Theory and Applications, Cambridge, MA: The MIT Press.

[13] FISHER, R. C. (1982): "Income and Grant Effects on Local Expenditure: The Flypaper Effect and other Difficulties", Journal of Urban Economics, 12: 324345.

[14] GAMKHAR, S. and A. SHAH (2007): "The Impact of Intergovernmental Fiscal Transfers: A Synthesis of the Conceptual and Empirical Literature", in R. BOADWAY and A. SHAH, eds.: Intergovernmental Fiscal Transfers: Principles and Practice, Washington, D.C.: The World Bank, pp. 225-258.

[15] GRAMLICH, E. (1969): "State and Local Governments and their Budget Constraint”, International Economic Review, 10: 163-182.

[16] GORDON, R. (1983): “An optimal taxation approach to fiscal federalism", Quarterly Journal of Economics, 98 (4): 567-586.

[17] HENDERSON, J. (1968): "Local Government Expenditures: A Social Welfare Analysis", Review of Economics and Statistics, 50: 156-163.

[18] HINES, J. J. JR., and R. H. THALER (1995): "The flypaper effect", Journal of Economic Perspectives, 9: 217-226.

[19] LOGAN, R. R. (1986): "Fiscal Illusion and the Grantor Government", Journal of Political Economy, 94: 1304-1318.

[20] LÓPEZ-LABORDA, J. and F. RODRIGO (2012): "Percepciones de los ciudadanos sobre las haciendas regionales: quién es y quién debería ser responsable de los servicios e impuestos autonómicos", XIX Encuentro de Economía Pública, Santiago de Compostela, 26 and 27, January 2012.

[21] McLURE, Ch. E. (1983): "Introduction: the revenue side of the assignment problem", in Ch. E. McLURE, ed.: Tax assignment in federal countries, Canberra: Centre for Research on Federal Financial Relations, The Australian National University, pp. xii-xix.

[22] MUSGRAVE, R. A. (1961): “Approaches to a Fiscal Theory of Political Federalism", in Universities-National Bureau Committee for Economic Research, ed. (1961): Public Finances, Needs Sources, and Utilization, Princeton, NJ: Princeton University Press and NBER, pp. 97-133.

[23] MUSGRAVE, R. A. (1983): "Who should tax, where and what?", in Ch. E. McLURE Jr., ed.: Tax Assignment in Federal Countries, Canberra: Centre for Research on Federal Financial Relations, The Australian National University, pp. 2-19.

[24] OATES, W.E. (1972): Fiscal Federalism, Nueva York: Harcourt Brace Jovanovich. 
[25] OATES, W.E. (1979): "Lump-Sum Grants have Price Effects", in P. MIESZKOWSKI and W.H. OAKLAND (1979): Fiscal Federalism and Grantsin-Aid, Washington: The Urban Institute.

[26] PERSSON, T. and G. TABELLINI (2000): Political Economics. Explaining Economic Policy, Cambridge, MA: The MIT Press.

[27] SAMUELSON, P. (1954): "The pure theory of public expenditure", Review of Economics and Statistics, 36: 387-389.

[28] SHAH, A., ed. (2007): The Practice of Fiscal Federalism: Comparative Perspectives, pp 288-316, Montreal and Kingston: McGill-Queen's University Press.

[29] WEINGAST, B., K. SHEPSLE and C. JOHNSEN (1981): "The Political Economy of Benefit and Costs: A Neoclassical Approach to Distributive Politics", Journal of Political Economy, 89(4): 642-664.

[30] WILSON, J. D. (2006): “Tax competition in a federal setting”, in E. AHMAD and G. BROSIO, eds.: Handbook of Fiscal Federalism, Cheltenham: Edward Elgar, pp. 339-354.

[31] ZABALZA, A. and J. LÓPEZ-LABORDA (2011): "The new Spanish system of intergovernmental transfers", International Tax and Public Finance, 18 (6): 750786. 